\section{Cancer risk 'slightly higher' for UK nuclear test participants}

\section{London}

A COMPREHENSIVE study of the health of men who took part in the UK atmospheric nuclear weapons tests in Australia and the Pacific between 1952 and 1968 has concluded that participation in the test programme has not had a detectable effect on life expectation nor on total risk of developing cancer. The results do however, suggest an increased risk of developing multiple myeloma and leukaemia.

The four-year study, published last week $^{*}$, was undertaken at the request of the Ministry of Defence by a team from the National Radiological Protection Board and the Imperial Cancer Research Fund, led by Sir Richard Doll.

For the study, mortality and cancer incidence rates of 22,347 men who participated in the tests and experimental programmes were compared with a similar group of 22,326 servicemen and civilians not involved in the tests. In both groups, mortality was less than expected from national rates, and the rates were closely similar for cancer and for all causes combined ( 80 and 83 per cent respectively for participants and controls of that expected for cancer and 80 and 79 per cent respectively of that expected for all other causes).

The large difference between the two groups in the mortality from leukaemia and multiple myeloma (22 deaths from leukaemia and 6 from multiple myeloma in the participants against 6 from leukaemia and none from myeloma in the controls) was mainly due to the extraordinarily low rates for the diseases in the controls. Compared to national rates, mortality from the two cancers increased by 13 and 11 per cent respectively in the participants.

Examination of rates from cancer in different groups of participants, divided according to measured doses of external irradiation, failed to show any trend for increases in leukaemia, multiple myeloma or all neoplasms with increase in recorded dose.

The authors say: "The evidence related to multiple myeloma and leukaemia (other than chronic lymphatic leukaemia) is confusing, and on balance it is concluded that there may well have been small hazards of both diseases associated with participation in the programme, but their existence is certainly not proven, and further research is desirable."

The authors estimate that some 17 per cent of participants were not traced and were consequently excluded from the study. They say, however, that from subanalysis they are satisfied that any resulting bias is small.
Commenting on the study in last week's British Medical Journal, Martin Gardner, professor of medical statistics at the Medical Research Council's Environmental Epidemiology Unit, says: "The preferred conclusion so far must surely be that some leukaemias, and probably multiple myelomas, have resulted from radiation exposure during the tests. This is a stronger conclusion than the authors are prepared to reach because of the lack of certainty in the findings.'

\section{New Delhi}

For the first time, Indian scientists have formed an independent non-governmental body to speak on nuclear issues of general concern and to keep a watch on the all-powerful Department of Atomic Energy (DAE).

The creation of the Indian Nuclear Society (INS), consisting of scientists, academics, intellectuals and representatives of the nuclear industry, ends the 40year monopoly of DAE, on which Indians

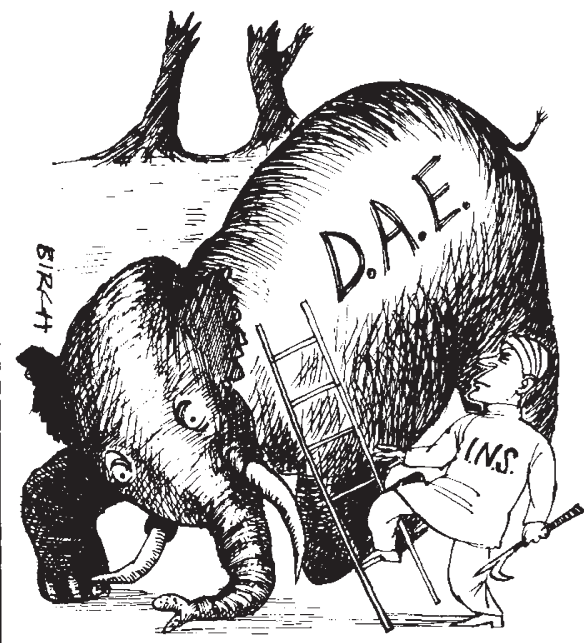

were forced to rely for any information good or bad - connected with the atom.

The response to INS from the scientific community has been so great that 660 scientists and engineers, some of them exemployees of DAE, enrolled as life members within a week of the formation of the society. Its chairman, Dr M.V.R. Ramanaiah, a retired scientist of the Bhabha Atomic Research Centre, says the society will function along the lines of the American Nuclear Society. "It will act as a watchdog and provide a forum for raising issues of relevance not only to nuclear
The Ministry of Defence, which commissioned the study after media publicity suggesting radiation-induced ill-health among test veterans, says it regards the results of the study "as fully vindicating its view that the radiological protection measures adopted were effective and that the chance of anyone suffering harm to health as a consequence of participation is extremely small". It has agreed to a recommendation from the study's authors to continue to observe mortality and cancer rates in the participants for a further ten years.

Simon Hadlington Darby, S.C. et al. Mortality and Cancer Indicence in UK Participants in UK Atmospheric Nuclear Weapon Tests and Experimental Programmes (National Radiological Protection Board-R214, HMSO, London).

\title{
New Indian nuclear watchdog will press for more openness
}

scientists, but to society as a whole."

Meaningful debates on issues of public concern are non-existent in India because of DAE's strict control over the flow of information from its projects, although all of them are supposedly for "peaceful purposes". DAE is also sensitive to criticism. A professor of the Jawaharlal Nehru University in New Delhi says the DAE caused his transfer from the Centre for Science Policy because of his critical articles.

Since its inception, DAE has been a closed establishment. It has been answerable directly to successive prime ministers and has operated under the provisions of the 25-year old Atomic Energy Act which, for example, prohibits any outside agency from even measuring the radioactive pollution near DAE's plants. In the past, DAE has been accused of either suppressing or providing incomplete details about leaks at the Tarapur plant, explosions in heavy-water plants, water pollution and death at a waste dump outside its nuclear fuel complex, as well as radiation hazards at its thorium plant in Kerala. Sites for nuclear stations or waste dumps are selected by DAE without any debate. In the absence of an independent body, DAE has a poor credibility rating. Scientists say that INS will in future provide a platform to discuss DAE's activities more openly.

According to Ramanaiah, the society will encourage nuclear energy and its applications and, at the same time, promote active participation of the public on nuclear issues. In carrying out its watchdog function, INS does not expect to embark on a collision course with DAE. Himself a firm believer in open policy, the new chairman of DAE, Dr M.R. Srinivasan, was instrumental in detaching the power wing from DAE and converting it into a public company last year.

K.S. Jayaraman 